\title{
Speciation of trace elements in sediments from Dongting Lake, central China
}

\author{
Z. G. Yao ${ }^{1}$, Z. Y. Bao ${ }^{1,2}$, P. Gao ${ }^{3}$, J. L. Zhang ${ }^{1}$, Y. P. Guo ${ }^{1}$, \\ Z. J. $\mathrm{Hu}^{3} \&$ B. L. $\mathrm{Li}^{3}$ \\ ${ }^{1}$ State Key Laboratory of Geological Processes and Mineral Resources, \\ China University of Geosciences, Wuhan, People's Republic of China \\ ${ }^{2}$ Faculty of Earth Sciences, China University of Geosciences, \\ Wuhan, People's Republic of China \\ ${ }^{3}$ Xinjiang Bureau of Geology and Mineral Exploration and Development, \\ Urumqi, People's Republic of China
}

\begin{abstract}
A BCR three-step sequential extraction procedure, with a sediment reference material (BCR701), was used in order to assess the environmental risk of $\mathrm{Cd}, \mathrm{Cr}$, $\mathrm{Cu}, \mathrm{Ni}, \mathrm{Pb}$, and $\mathrm{Zn}$ in contaminated sediment from Dongting Lake. The total metal content was determined as well. Dongting Lake, the second largest fresh-water lake in China, contains three China wetlands of international importance. In the Dongting Lake sediments, the trace elements $(\mathrm{Cu}, \mathrm{Zn}, \mathrm{Cr}$, and $\mathrm{Ni}$ ) analyzed are mainly distributed in a residual phase at an average percentage greater than $60 \%$ of the total metals, especially $79 \%$ for $\mathrm{Cr}$ and $90 \%$ for $\mathrm{Ni}$; but $\mathrm{Pb}$ in $\mathrm{Fe} / \mathrm{Mn}$ oxhydroxides phase (59\%) and $\mathrm{Cd}$ in soluble species and carbonates $(51 \%)$. The potential risk to the lake's water contamination was highest in East Dongting Lake based on the calculated contamination factors. Therefore, there is an urgent need to protect Dongting Lake from anthropogenic sources of pollution to reduce environmental risks.
\end{abstract}

Keywords: Dongting Lake, sediment, geo-accumulation index, speciation, contamination factor, trace elements, major elements.

\section{Introduction}

Dongting Lake $\left(28^{\circ} 40^{\prime}\right.$ to $29^{\circ} 40^{\prime} \mathrm{N}$ and $112^{\circ} 00^{\prime}$ to $\left.113^{\circ} 30^{\prime} \mathrm{E}\right)$, the second largest freshwater lake in China, lies in the south of middle Yangtze River within Hunan 
province, China (Fig.1). Its catchment's area ca. is $262800 \mathrm{~km}^{2}$, accounting for ca. 14\% of Yangtze River. The lake covers an area of $2691 \mathrm{~km}^{2}$ and its period of exchangeable water no more than 20 days. So it becomes the largest and most important flood-controlling lake in Yangtze River (Jin [1]).

It currently serves 65 million people in the Yangtze River Delta. Its waters are used for drinking water, flood control, shipping, waste disposal, fisheries, aquaculture and farming, and a source for tourism and recreation. Yangtze River pours its water from the northwest into the lake through three river channels named Songzi, Hudu and Ouzi river channels (ab. Song-Ou channels). Other four major tributaries, namely, Xiangjiang, Zishui, Yuanjiang and Lishui rivers, discharge water into the Lake from south, west and northwest, respectively. All of waters flow northeastward out of Dongting Lake through Chenglingji back into Yangtze River and finally, discharge into East China Sea. Dongting Lake mainly consists of East Dongting Lake, South Dongting Lake (including Wanzi Lake and Hengling Lake) and West Dongting Lake, they boast abundant animal and plant life, especially birds and waterfowl and become wetlands of international importance, protected by the Ramsar Convention [2].

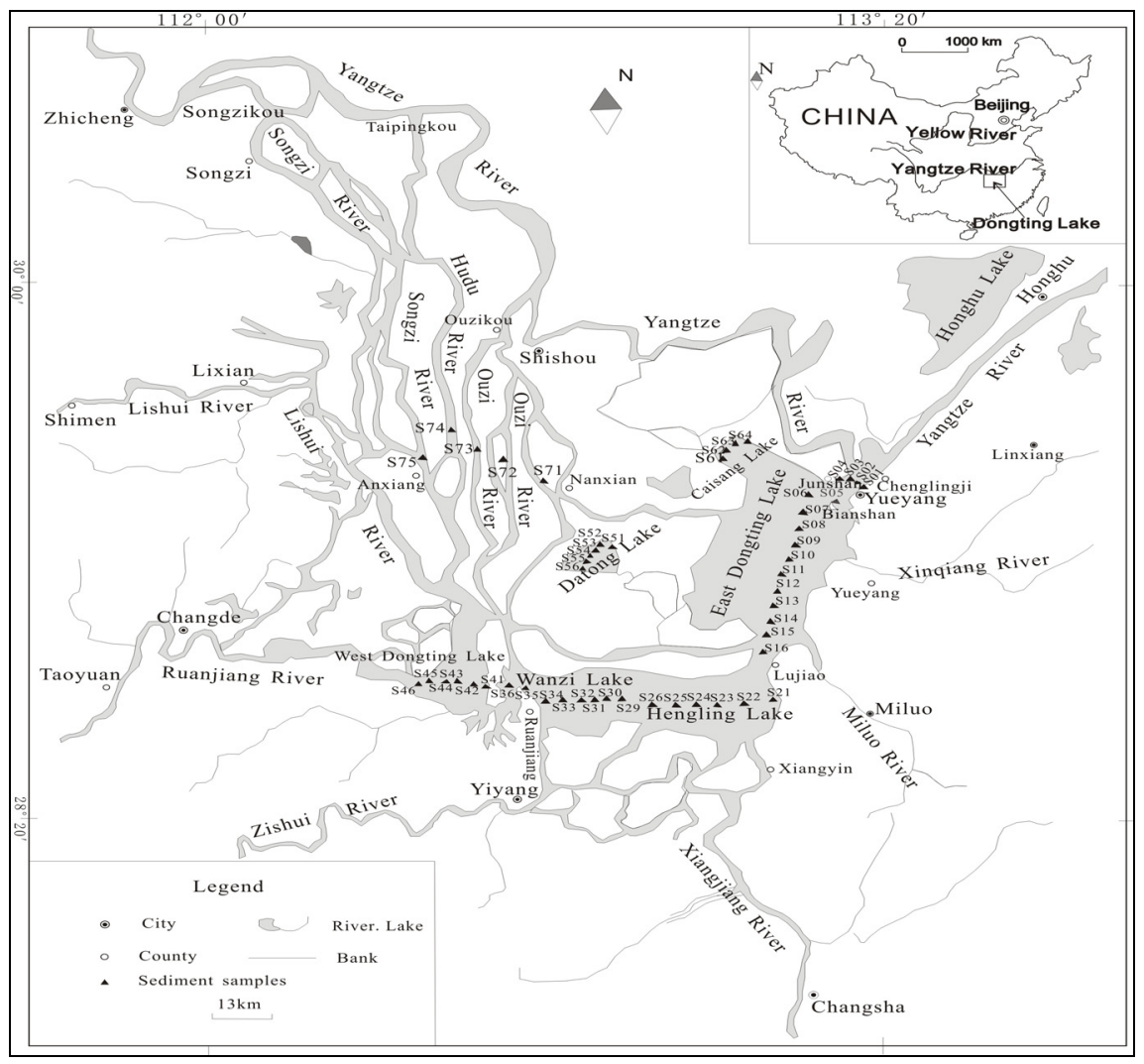

Figure 1: $\quad$ Schematic map of sampling points in Dongting Lake. 
During the last decade, researchers have mainly studied the water pollution of Dongting Lake [3-5], and thought that the overall water quality in the lake region was mesotrophic. In recent yeas, the increased anthropogenic inputs to the lake have resulted in a deterioration of the water quality in many parts of the lake. In 2005, the arsenic and cadmium abrupt environmental events took place in Xiangjiang River drainage area [6]. Although eutrophication and trace element pollution are two key environmental problems in Dongting Lake, a study on the speciation of trace elements in the sediments of this lake has not previously been undertaken.

Measurement of total metal concentrations is useful to evaluate the heavy metal burden but their mobility depends strongly on their specific chemical forms or ways of binding. However, the significance of the analytical results is related to the extraction scheme used. Sediment samples are subject to sequential extraction by using chemicals of decreasing $\mathrm{pH}$ and increasing oxidizing strength to remove the operationally-defined host fractions. Some studies have examined the speciation of metals in the sediments [7-10]. But if the scheme is lack of comparability and quality control, it will neither allow the results to be compared worldwide nor the procedures to be validated. With the aim to harmonize different extraction schemes, the Community Bureau of Reference (BCR) proposed a three-step extraction procedure with a set of the sediment reference material, such as CRM601, CRM602 and BCR701. Although some researchers still prefer to use longer and more complicated methods in order to achieve metal information, the use of the BCR method is on the increase [10]. Unfortunately, the application of the BCR method is very limited in China. In the study we report an investigation into the speciation distribution of trace elements $(\mathrm{Cd}, \mathrm{Cr}$, $\mathrm{Cu}, \mathrm{Ni}, \mathrm{Pb}$ and $\mathrm{Zn}$ ) in the flow-through water lake in inland. The major objectives of this study are: (1) to extend and promote the application of the BCR method in China; (2) to assess the risk of Dongting Lake water contamination by lake sediment.

\section{Materials and methods}

\subsection{The collection of the samples}

Bottom sediment samples were collected from 53 sampling points in November 2004 (Fig. 1) by means of a mud-grab $(10 " \times 6 " \times 5$ ") which can capture of some $2 \mathrm{~kg}$ of sediment material with a penetration depth exceeding $25 \mathrm{~cm}$. The samples were immediately sealed and stored at $4{ }^{\circ} \mathrm{C}$ until arriving at our laboratory. At the laboratory, the samples were air-dried, disaggregated by mortar and pestle, and finally the fraction $<0.063 \mathrm{~mm}$ was chosen to be chemical analyzed. Next, two sub-samples were taken, depending on the sort of analysis to be undertaken.

\subsection{Analytical methods}

One sub-sample was used to determine the total metal contents. With this purpose, an acid decomposition with $\mathrm{HNO}_{3}+\mathrm{HF}+\mathrm{HClO}_{4}+\mathrm{H}_{2} \mathrm{O}_{2}$ was used for the 
$\mathrm{Cd}, \mathrm{Cr}, \mathrm{Cu}, \mathrm{Ni}, \mathrm{Pb}$ and $\mathrm{Zn}$ by the inductively coupled plasma and mass spectrometry ICP-MS (Termoelemental X7, ICP-MS).

The other sub-sample was subjected to the BCR procedure [11], with slight modifications in the last step. Extractions were performed using the reagents given in Table1. The residue from Step3 was digested in aqua regia (Step4) with microwave-assisted digestion procedure by Mars-5 microwave labstation (CEM Company, USA). The residue was placed in a PTFE reactor with $65 \% \mathrm{HNO}_{3} 4$ $\mathrm{ml}$ and $37 \% \mathrm{HCl} 12 \mathrm{ml}$. Then it was heated following a three-stage digestion programmer: Step 1 (250W, 2 min); Step 2 (400W, 2 min); Step 3 (500w, 8min). The concentrations of trace metals were determined by atomic absorption spectrophotometer (AAS) using a Perkin-Elmer 800 AAS.

Table 1: $\quad$ The three-step BCR procedures [11].

\begin{tabular}{|c|c|c|c|}
\hline & Fraction & Nominal Target phase (s) & Procedure (revised $B C R$ ) \\
\hline Step1 & $\begin{array}{l}\text { Exchangeable, } \\
\text { water and acid } \\
\text { soluble }\end{array}$ & $\begin{array}{l}\text { Soluble species, carbonates, } \\
\text { cation exchange sites }\end{array}$ & $0.11 \mathrm{~mol} \mathrm{l}^{-1}$ acetic acid \\
\hline Step2 & Reducible & $\begin{array}{l}\text { Iron and manganese } \\
\text { oxhydroxides }\end{array}$ & $\begin{array}{l}0.5 \text { mol l}^{-1} \text { hydroxylammonium } \\
\text { chloride at } \mathrm{pH} 1.5\end{array}$ \\
\hline Step3 & Oxidiable & Organic matter and sulphides & $\begin{array}{l}\text { Hydrogen peroxide followed by } \\
1.0 \mathrm{~mol} \mathrm{~L}^{-1} \text { ammonium acetate at } \\
\mathrm{pH} 2\end{array}$ \\
\hline Step4 & Residual & & Aqua regia \\
\hline
\end{tabular}

\subsection{The deviation of experimental data}

All reagents were analytical grade or Suprapur quality. Standard solutions were prepared by serial dilution of $1000 \mathrm{mg} \mathrm{l}^{-1}$ Spectroscan solution of the appropriate element. All standards and reagent solutions were stored in polyethylene bottles. Duplicate measurements showed that concentrations of elements are reproducible with an analytical precision better than $10 \%$.

For the BCR procedure, validation of instrument accuracy and precision was carried out using a certified reference material, BCR-701. For an internal check on the procedure, the element concentrations from the three steps plus residual were compared with the concentrations of total content (by ICP-MS). Table 2 shows the results of the analysis of BCR-701 reference samples.

\section{Results}

\subsection{Contents of total trace elements}

The concentrations of 6 trace metals $(\mathrm{Cd}, \mathrm{Cr}, \mathrm{Cu}, \mathrm{Ni}, \mathrm{Pb}$ and $\mathrm{Zn}$ ) in sediments collected from Dongting Lake and published values for sediment/soil are listed in Table 3. The average values of $\mathrm{Cd}, \mathrm{Cu}, \mathrm{Pb}$ and $\mathrm{Zn}$ analyzed in sediments are higher than the corresponding values of the soil in the Dongting Lake alluvium plain (ab., SDTAP) [13], especially, the average of $\mathrm{Cd}$ is up to $2.7 \mathrm{mg} \mathrm{kg}^{-1}$; additionally, they are also higher than the background levels of Soil (I Soil, [14]) 
and those corresponding values of average shale [15]; however, the averages of 4 metals are lower than the threshold values for severely polluted soil (III Soil, [14]) except the Cd higher than III Soil; compared with Canadian fresh-water sediment, the concentrations of 6 heavy metals are higher than the Threshold Effect Level (TEL) of Canada EPA (Environment Protect Agency) Interim Sediment Quality Guideline (ISQG) and are lower than Probable Effect Level (PET) [16]. The TEL means the threshold levels of sediment contamination by various elements that can be tolerated by the majority of benthic organisms; the PEL denotes the probable levels of sediment contamination by various elements that cannot be tolerated by the majority of benthic organisms. For the $\mathrm{Cr}$ and $\mathrm{Ni}$, both are similar to the SDTAP, average shale and I Soil, but slightly higher than PEL value. It is obvious that Dongting Lake area has suffered from some extent heavy metal contamination, especially $\mathrm{Cd}$, while $\mathrm{Cr}$ and $\mathrm{Ni}$ probably mainly stem from the regional parent rock.

Table 2: $\quad$ Trace element contents of the BCR-701, and comparison of total contents (unit: $\mathrm{mg} \mathrm{kg}^{-1}$ ).

\begin{tabular}{llllllll}
\hline Metal & BCR-701 & Step 1 & Step 2 & Step 3 & Step 4 & ESteps & $\begin{array}{l}\text { Total } \\
\text { con. }\end{array}$ \\
\hline $\mathrm{Cu}$ & Certified $^{\mathrm{a}}$ & $49.3 \pm 1.7$ & $124 \pm 3$ & $55.2 \pm 4.0$ & & & 275 \\
& Analyzed $^{\mathrm{b}}$ & $45.88 \pm 0.8$ & $117 \pm 2.5$ & $66.64 \pm 4.8$ & $60.46 \pm 3.3$ & $289 \pm 11$ & $296 \pm 13$ \\
$\mathrm{~Pb}$ & Certified $^{\mathrm{a}}$ & $3.18 \pm 0.21$ & $126 \pm 3$ & $9.3 \pm 2.0$ & $11 \pm 5.2$ & & $143 \pm 6$ \\
& Analyzed $^{\mathrm{b}}$ & $2.80 \pm 0.4$ & $107 \pm 5.0$ & $9.28 \pm 2.0$ & $24.70 \pm 1.6$ & $144 \pm 9$ & $139 \pm 5$ \\
$\mathrm{Zn}$ & Certified $^{\mathrm{a}}$ & $205 \pm 6$ & $114 \pm 5$ & $45.7 \pm 4.0$ & $95 \pm 13$ & & $454 \pm 19$ \\
& Analyzed $^{\mathrm{b}}$ & $186 \pm 3.0$ & $102 \pm 2.5$ & $45.3 \pm 3.3$ & $127 \pm 2.5$ & $460 \pm 11$ & $446 \pm 10$ \\
$\mathrm{Cd}$ & Certified $^{\mathrm{a}}$ & $7.34 \pm 0.35$ & $3.77 \pm 0.28$ & $0.27 \pm 0.06$ & $0.13 \pm 0.08$ & & $11.7 \pm 1.0$ \\
& Analyzed $^{\mathrm{b}}$ & $7.12 \pm 0.45$ & $3.56 \pm 0.27$ & $0.28 \pm 0.07$ & $0.23 \pm 0.03$ & $11.8 \pm 0.82$ & $12.9 \pm 0.6$ \\
$\mathrm{Cr}$ & Certified $^{\mathrm{a}}$ & $2.26 \pm 0.16$ & $45.7 \pm 2.0$ & $143 \pm 7$ & & & 272 \\
& Analyzed $^{\mathrm{b}}$ & $2.61 \pm 0.26$ & $49.8 \pm 2.6$ & $152 \pm 5$ & $120 \pm 4$ & $324 \pm 12$ & $300 \pm 11$ \\
$\mathrm{Ni}$ & Certified $^{\mathrm{a}}$ & $15.4 \pm 0.9$ & $26.6 \pm 1.3$ & $15.3 \pm 0.9$ & $41.4 \pm 4$ & & $103 \pm 4$ \\
& Analyzed $^{\mathrm{b}}$ & $14.2 \pm 0.5$ & $25.9 \pm 0.6$ & $17.3 \pm 0.5$ & $52.9 \pm 1.6$ & $110 \pm 3$ & $107 \pm 4$ \\
\hline
\end{tabular}

${ }^{a}$ Unweighted mean values \pm uncertainty [12].

${ }^{\mathrm{b}}$ Mean values \pm standard deviation, for $\mathrm{n}=5$.

The greatest concentration levels of the metal analyzed are found in the sediments collected from Lujiao to Chenglingji within East Dongting Lake. The section is near the so-called "the main sail-route of Xiangjiang River". Xiangjiang River is the biggest one of Dongting Lake drainage area. According to the report [17], the middle and downriver of Xiangjiang River is of the most crowed population, speeding economical development and the most energy consumption in Hunan province; by the end of 2002, the population of Xiangjiang valley is ca. 39 million people; the discharge amount of pollutants via Xiangjiang in 2002, they are $111600 \mathrm{t}$ for COD, $1.85 \mathrm{t}$ for mercury, 18.58t for lead, 75.93t for cyanide and so on; at the same time, domestic pollution is aggravating, only in 2003, the discharge of domestic sewage reaches to 8 hundred million tons from main cities in Xiangjiang valley but it is severely lagged for the city sewage treatment facility and management. What is more, East Dongting Lake also receives large amount of polluted effluents from the 
industrial and domestic sewage in the vicinity of the lake [5]. On the contrary, in Caisang Lake, the concentrations of these 6 trace metals all approach to those of Song-Ou channels and the SDTAP, which reflects the sediments of Caisang Lake may root in forepast diluvia deposits of Yangtze River and are characteristic of unpolluted sediments. Datong Lake has relative high heavy metal concentration level, which may be ascribed to the relative sealed condition. The decreasing order of heavy metal concentration levels is: East Dongting Lake $>$ Datong Lake $>$ Hengling Lake $>$ Wanzi Lake $>$ West Dongting Lake $>$ Caisang Lake.

Table 3: Mean concentrations of trace metals from Dongting Lake sediments and published mean sediment values in some countries.

\begin{tabular}{lllllll}
\hline \multirow{2}{*}{$\begin{array}{l}\text { Sites and } \\
\text { the number of simples (n) }\end{array}$} & \multicolumn{6}{c}{ Trace elements (unit: $\left.\mathrm{mg} \mathrm{kg}^{-1}\right)$} \\
\cline { 2 - 7 } & $\mathrm{Cu}$ & $\mathrm{Pb}$ & $\mathrm{Zn}$ & $\mathrm{Cd}$ & $\mathrm{Cr}$ & $\mathrm{Ni}$ \\
\hline Caisang lake (n=5) & $38 \pm 8$ & $31 \pm 6$ & $91 \pm 18$ & $0.4 \pm 0.2$ & $84 \pm 13$ & $40 \pm 6$ \\
Datong lake (n=6) & $67 \pm 5$ & $44 \pm 4$ & $120 \pm 10$ & $0.6 \pm 0.1$ & $110 \pm 9$ & $49 \pm 4$ \\
West Dongting lake (n=6) & $30 \pm 6$ & $34 \pm 7$ & $103 \pm 21$ & $0.7 \pm 0.4$ & $66 \pm 7$ & $32 \pm 4$ \\
Wanzi lake (n=8) & $36 \pm 14$ & $39 \pm 13$ & $106 \pm 25$ & $0.7 \pm 0.2$ & $74 \pm 11$ & $36 \pm 7$ \\
Hengling lake (n=6) & $38 \pm 9$ & $49 \pm 11$ & $112 \pm 12$ & $0.7 \pm 0.2$ & $78 \pm 9$ & $37 \pm 5$ \\
East Dongting lake (n=12) & $68 \pm 16$ & $79 \pm 23$ & $209 \pm 67$ & $7.3 \pm 4.2$ & $96 \pm 16$ & $42 \pm 8$ \\
The average values of the & $51 \pm 21$ & $53 \pm 24$ & $140 \pm 61$ & $2.7 \pm 3.7$ & $87 \pm 18$ & $40 \pm 8$ \\
whole Dongting Lake (n=43) & & & & & & \\
Song-Ou channels (n=5) & $46 \pm 3$ & $36 \pm 6$ & $105 \pm 6$ & $0.4 \pm 0.1$ & $81 \pm 6$ & $38 \pm 4$ \\
Chenglingji (n=5) & $82 \pm 10$ & $83 \pm 10$ & $211 \pm 24$ & $5.5 \pm 2.2$ & $100 \pm 8$ & $44 \pm 4$ \\
SDTAP & 45.9 & 27.8 & 99.7 & 0.2 & 83.9 & 41.8 \\
Average shale & 45 & 20 & 95 & 0.3 & 90 & 68 \\
I Soil & 35 & 35 & 100 & 0.2 & 90 & 40 \\
IIIsoil & 400 & 500 & 500 & 1.0 & 400 & 200 \\
TEL & 36 & 35 & 123 & 0.6 & 37 & 18 \\
PEL & 197 & 91 & 315 & 3.5 & 90 & 36 \\
\hline
\end{tabular}

\subsection{Chemical speciation of trace elements in sediments}

Figure 2 shows, in percent bar graphs, the mean distribution of the heavy metals on the four fractions obtained by the BCR procedure. We can observe that in the sediments of Caisang Lake, $>50 \%$ of $\mathrm{Cu}, \mathrm{Zn}, \mathrm{Cr}$ and $\mathrm{Ni}$ are extracted in the residual fraction, Step4, especially $\mathrm{Cr}(91 \%)$ and $\mathrm{Ni}(78 \%)$. According to Rubio et al. [7] and Samanidou and Fytianos [9], this fraction corresponds to the metal with a natural origin and will not be remobilized into the aquatic medium in the conditions given in nature.

In the sediments from East Dongting Lake, the percentages of the metals associated with the residual fraction, are notably lower than those obtained on Caisang Lake, except $\mathrm{Cr}$ and $\mathrm{Ni}$ similar. This fact is especially marked for $\mathrm{Cd}$ (23\% in Caisang Lake and 3.8\% in East Dongting Lake) and $\mathrm{Pb}$ (41\% in Caisang Lake and $26 \%$ in East Dongting Lake). We must take into account that the sediments of East Dongting Lake are remarkably more polluted than those of 
other sub-lakes. In the sediments of other sub-lakes under study, the proportion of metals in Step4 is similar to each other. Additionally, $62 \%$ of $\mathrm{Cu}, \mathrm{Zn}, \mathrm{Cr}$ and $\mathrm{Ni}$ exist in the residual fraction, with from $26 \%$ to $36 \%$ of $\mathrm{Pb}$ and from $17 \%$ to $22 \%$ of $\mathrm{Cd}$ in this fraction.

East Dongting Lake

$\square$ Step1 $\square$ Step2 $\square$ Step3 $\square$ Step4

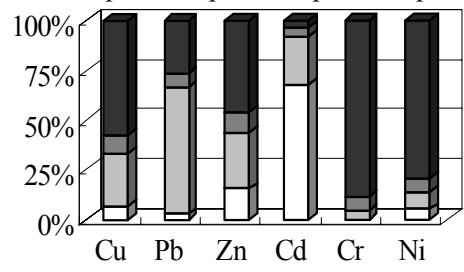

Datong Lake

$\square$ Step $1 \square$ Step2 $\square$ Step3 $\square$ Step4

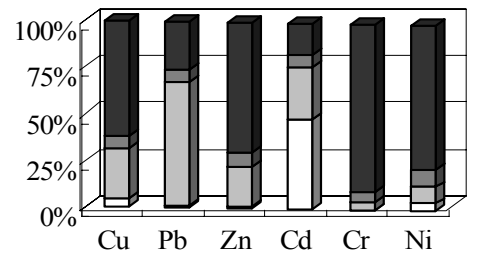

Wanzi Lake

$\square$ Step1 $\square$ Step2 $\square$ Step3 $\square$ Step4

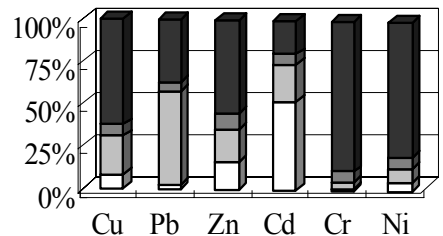

Caisang Lake

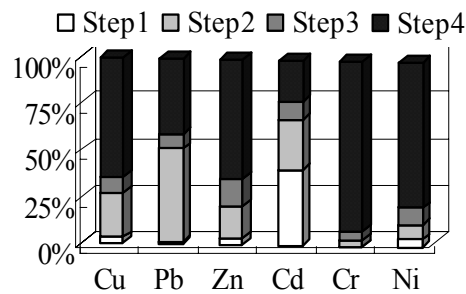

West Dongting Lake

$\square$ Step $1 \square$ Step2 $\square$ Step3 $\square$ Step4

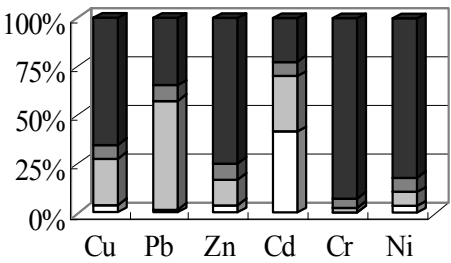

Hengling Lake

$\square$ Step1 $\square$ Step2 $\square$ Step3 $\square$ Step4

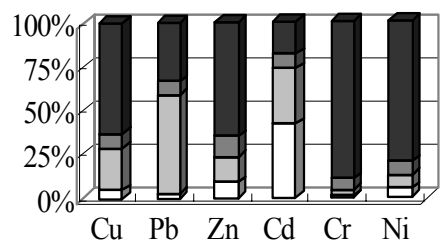

Figure 2: $\quad$ Speciation of trace elements in the sediments of Dongting Lake.

For all sub-lakes in this study, the portion of metals is Step1 (exchangeable and acid soluble fractions) is very low, but Cd surpasses $40 \%$, especially $68 \%$ in East Dongting Lake. In this phase, we have only detected $\mathrm{Cu}$ the range from 3\% to $8 \%$ ), $\mathrm{Pb}$ from $1 \%$ to $3 \%, \mathrm{Ni}$ from $4 \%$ to $6 \%$ and $\mathrm{Cr}$ in all sediments analyzed less than $0.7 \%$; we also observed for diversification of $\mathrm{Zn}, 16 \%$ for East Dongting Lake and Wanzi Lake and the scope from 1\% to $9 \%$ for other sublakes. Taking into consideration the high mobility and potential bioavailability of heavy metals in this fraction and their total concentration (Table 3), it can be concluded that those sediments which contain the high percentages of $\mathrm{Cd}$ and $\mathrm{Zn}$ in Step1 could have potentially hazardous effects on the environment. In Step2, 
the largest amount of lead is associated the iron and manganese oxide fractions $(>50 \%)$. Fe/Mn oxides exist as nodules, concretions, cement between particles or as a coating on particles and are excellent trace element scavengers [8]. The results obtained for $\mathrm{Cd}, \mathrm{Pb}, \mathrm{Zn}$ and $\mathrm{Ni}$ are similar to those reported by Marguí et al. [10] for mining wastes from $\mathrm{Pb}-\mathrm{Zn}$ mining areas of Cartagena, Spain. The average percentages of 6 trace elements in organic and sulphide phases, Step 3, range from $5 \%$ to $10 \%$. Under oxidizing conditions, metals present in the fraction (due to complexation and peptisation) and living organisms (as a result of bioaccumulation of metals) may be remobilized into the aquatic environment. In general, the mobility for metals associated with the reducible fraction is higher than those in the organic/sulfide fraction under reducing conditions [18].

Table 4: Individual and global contamination factors of six elements in Dongting Lake sediments.

\begin{tabular}{llllllll}
\hline Section & \multicolumn{9}{c}{ Individual contamination faction } & Global \\
\cline { 2 - 6 } & $\mathrm{Cu}$ & $\mathrm{Pb}$ & $\mathrm{Zn}$ & $\mathrm{Cd}$ & $\mathrm{Cr}$ & $\mathrm{Ni}$ & $\begin{array}{l}\text { contamination } \\
\text { factor }\end{array}$ \\
\hline Chenglingji & 1.0 & 3.5 & 1.1 & 30.6 & 0.2 & 0.3 & 36.6 \\
East Dongting Lake & 0.7 & 2.8 & 1.2 & 25.0 & 0.1 & 0.3 & 30.1 \\
Datong Lake & 0.6 & 2.8 & 0.4 & 4.8 & 0.1 & 0.3 & 9.2 \\
West Dongting Lake & 0.5 & 1.9 & 0.8 & 3.6 & 0.1 & 0.2 & 6.7 \\
Wanzi Lake & 0.6 & 1.7 & 0.5 & 4.1 & 0.1 & 0.3 & 7.6 \\
Hengling Lake & 0.6 & 2.0 & 0.6 & 4.4 & 0.1 & 0.2 & 7.9 \\
Caisang Lake & 0.6 & 1.4 & 0.7 & 3.4 & 0.1 & 0.3 & 6.3 \\
\hline
\end{tabular}

\subsection{Assessment based on contamination factors}

So as to study metal potential risk to the lake water, contamination factors were calculated. Table 4 shows the individual contamination factors (ICF) and the global contamination factor (GCF) for these six elements in the Dongting Lake sediments analyzed. The ICF are defined as the sum of heavy metal concentration in the non-residual phases of the sample divided by the residual phase content. The GCF for each site was calculated by summing the ICF for all the six elements obtained from a site [19]. The applicability of many toxic elements in calculating GCF is significant because it reflects the overall potential risks posed by the toxic elements to the environment and biota.

East Dongting Lake has higher individual and global contamination factors compared to other sections. Nickel and chromium poses the lowest risks to the Lake water contamination. The decreasing order of contamination for trace metals is as follows: $\mathrm{Cd}>\mathrm{Pb}>\mathrm{Zn}>\mathrm{Cu}>\mathrm{Ni}>\mathrm{Cr}$. The decreasing order of environmental risk for sub-likes is: East Dongting Lake $>$ Datong Lake $>$ Hengling Lake $>$ Wanzi Lake $>$ West Dongting $>$ Caisang Lake in this study. The remobilization of metals is influenced by many factors such as chemical speciation, the physico-chemical characters and $\mathrm{pH}$ of the water body. 


\section{Conclusion}

In this study the usefulness of the optimized BCR procedure by using a certified reference material, BCR-701 for prediction metal mobility $(\mathrm{Cu}, \mathrm{Pb}, \mathrm{Zn}, \mathrm{Cd}, \mathrm{Cr}$ and Ni) from Dongting Lake sediments has been done. From the results of the speciation analysis it can be concluded that a significant proportion of $\mathrm{Cd}$ (up to $68 \%$ ) is present as exchangeable and acid-soluble species and $>50 \%$ of $\mathrm{Pb}$ in iron and manganese oxide fractions in bottom sediments collected in Dongting Lake. Otherwise, the predominance of reducible $\mathrm{Cr}$ and $\mathrm{Ni}$ has been found in all the sediments. Comparison among the chemical speciation of trace elements in these sub-lakes from the BCR scheme, The decreasing order of contamination for trace metals is as follows: $\mathrm{Cd}>\mathrm{Pb}>\mathrm{Zn}>\mathrm{Cu}>\mathrm{Ni}>\mathrm{Cr}$. The decreasing order of environmental risk for sub-likes is: East Dongting Lake $>$ Datong Lake $>$ Hengling Lake $>$ Wanzi Lake $>$ West Dongting $>$ Caisang Lake in this study. The trace element pollutants in the sediments of Dongting Lake have mainly accumulated in the parts from Lujiao to Chenglingji within East Dongting Lake, which receives large amounts of municipal and industrial sewage in the vicinity of Yueyang City and via Xiangjiang River. It is an extremely urgent task to restore Dongting Lake from heavy metal contamination, especially East Dongting Lake.

\section{References}

[1] Jin, X.C., Environment of China Lakes, Ocean Press: Beijing, China, (vol.2) pp. 72-107, 1995 (In Chinese).

[2] Ramsar Convention, ramsar.org/sitelist.doc.

[3] Bu, Y.X. \& Chai, M., Preliminary assessment of economic loss caused by water pollution in Dongting Lake. Yangtze River, 32(4), pp. 27-30, 2001 (in Chinese).

[4] Dai, Y.Z., Tang, S.Y. \& Zhang, J.B., The distribution of zoobenthos species and bio-assessment of water quality in Dongting Lake. Acta Ecologica Snica, 20(3), pp. 277-282, 2000 (in Chinese).

[5] Lu, H.W., Zeng, G.M. \& Xie, G.X., The regional ecological risk assessment of the Dongting Lake watershed. Acta Ecologica Snica, 23(12), pp. 2520-2531, 2003(in Chinese).

[6] Office of Hunan Water Resources Web Site, Changsha, Hunan, China, www.hnwr.gov.cn/news/html/2006/01.

[7] Rubio, R., López-Sánchez, J.F. \& Rauret, G., La especiación sólida de trazas de metals en sediments: Aplicación a sedimentos muy contaminados. Anal. De Quim. 87, pp. 599-605, 1991.

[8] Jenne, E.A., Trace inorganics in water. Adv. Chem. Ser., 73, 337-387, 1968.

[9] Samanidou, V. \& Fytianos, K., Partitioning of heavy metals into selective chemical fractions in sediments from rivers in northern Greece. Sci. Total Env. 67, pp. 279-285, 1987. 
[10] Marguí, E., Salvadó, V., Queralt, I. \& Hidalgo, M., Comparison of threestage sequential extraction and toxicity characteristic leaching tests to evaluate metal mobility in mining wastes. Analytica Chimica Acta, 524, pp. 151-159, 2004.

[11] Mossop, K.F. \& Davidson, C.M., Comparison of original and modified BCR sequential extraction procedures for the fractionation of copper, iron, lead, manganese and zinc in soils and sediments. Analytica Chimica Acta, 478, pp. 111-118, 2003.

[12] European Commission-Joint Research Centre, Institute for Reference Materials and Measurement (IRMM), www.irmm.jrc.be/mrm.html.

[13] Tong, T., Element concentrations in river delta sediment and mineral resources potential in the drainage basin: A case study in the Xiangjiang, Zishui, Yuanjiang and Lishui rivers basin. Quaternary Science, 25(3), pp. 298-305, 2005 (in Chinese).

[14] China Standards Consulting Service Network, Environmental Quality Standard for Soils in China, GB 15618-1995, CNS Online Service, http://www.cnsonline.com.tw/en/.

[15] Turekian, K.K. \& Wedepohl, K.H., Distribution of the elements in some major units of the earth's crust. Bull. Geol. Soc. Am., 72, pp. 175-192, 1961.

[16] Smith, S.L., The development and implementation of Canadian sediment quality guidelines. Development and progress in sediment quality assessment: rational, challenge, techniques \& strategies. SPB Academic Publishing: Amsterdam, pp. 233-249, 1996.

[17] Office of China View Web Site, XINHUA online web site, Beijing, China, news.xinhuanet.com/forcus/2004-09/15.

[18] Rule, J.H. \& Alden III, R.W., Partitioning of Cd in geochemical fractions of anaerobic estuarine sediments. Estuar. Coastal Shelf Sci., 34, 487-499, 1992.

[19] Barona, A., Aranguiz, I. \& Elí as, A., Assessment of metal extraction, distribution and contamination in surface soils by a 3-step sequential extraction procedure. Chemosphere, 39(1), pp. 1911-1922, 1999. 